\title{
Estratégias ótimas de irrigação do feijão-caupi para produção de grãos verdes
}

\author{
Herbert Moraes Moreira Ramos ${ }^{(1)}$, Edson Alves Bastos ${ }^{(2)}$, Aderson Soares de Andrade Júnior ${ }^{(2)}$ \\ e Waldir Aparecido Marouelli(3)
}

\begin{abstract}
(1)Universidade Federal do Piauí, Programa de Pós-graduação em Agronomia, Caixa Postal 12.168, CEP $64049-550$ Teresina, PI. E-mail: moreiraramos@uol.com.br (2)Embrapa Meio-Norte, Caixa Postal 01, CEP 64006-220 Teresina, PI. E-mail: edson@cpamn.embrapa.br, aderson@cpamn.embrapa.br ${ }^{(3)}$ Embrapa Hortaliças, Caixa Postal 218, CEP 70359-970 Brasília, DF. E-mail: marouelli@cnph.embrapa.br
\end{abstract}

Resumo - O objetivo deste trabalho foi determinar estratégias ótimas de irrigação do feijão-caupi (Vigna unguiculata) para a produção de grãos verdes, com a água como fator limitante da produção e diferentes valores de preço do produto. O experimento foi conduzido na Embrapa Meio-Norte, em Teresina, PI, entre setembro e novembro de 2009. Foram avaliadas cinco lâminas de irrigação, estabelecidas com base em frações da evapotranspiração de referência $(25,50,75,100$ e 125\% da ETo), e as cultivares BRS Guariba e BRS Paraguaçu de feijão-caupi. Aplicou-se a irrigação por sistema de aspersão convencional fixo. Utilizou-se o delineamento experimental de blocos ao acaso, com quatro repetições e parcelas subdivididas (cultivares). As lâminas de irrigação entre 290 e 325 mm (108 e 130\% da ETo) (BRS Paraguaçu) e entre 325 e 363 mm (130 e 153\% da ETo) (BRS Guariba) maximizam a receita líquida na faixa de variação de preço do produto entre US\$ 0,75 e 2,00 $\mathrm{kg}^{-1}$, para a cultivar BRS Paraguaçu, e entre US\$ 0,50 e 2,00 $\mathrm{kg}^{-1}$, para a BRS Guariba. A cultivar BRS Guariba apresenta melhor desempenho econômico que a BRS Paraguaçu.

Termos para indexação: Vigna unguiculata, evapotranspiração, irrigação com deficit, planejamento de irrigação.

\section{Optimal irrigation strategies for cowpea green bean production}

\begin{abstract}
The objective of this work was to determine optimal strategies of irrigation for cowpea (Vigna unguiculata) for the production of green bean, with water as the limiting yield factor and different values for the price of the product. The experiment was carried out at Embrapa Meio-Norte, in Teresina, PI, Brazil, from September to November 2009. Five irrigation depths, established based on fractions of reference evapotranspiration $(25,50,75,100$, and $125 \%$ of ETo), and the BRS Guariba and BRS Paraguaçu cowpea cultivars were evaluated. Irrigation was done with a conventional fixed sprinkling system. The experimental design was a randomized complete block with four replicates, in a split-plot arrangement (cultivars). The irrigation depths from 290 to $325 \mathrm{~mm}$ (108 to 130\% of ETo) (BRS Paraguaçu) and from 325 to $363 \mathrm{~mm}$ (130 to $153 \%$ of ETo) (BRS Guariba) maximize the liquid income, considering the price range of the product from US\$ 0.75 to $2.00 \mathrm{~kg}^{-1}$, for the cultivar BRS Paraguaçu, and from US\$ 0.50 to $2.00 \mathrm{~kg}^{-1}$, for BRS Guariba. The cultivar BRS Guariba shows better economic performance than BRS Paraguaçu.
\end{abstract}

Index terms: Vigna unguiculata, evapotranspiration, deficit irrigation, planned irrigation.

\section{Introdução}

O feijão-caupi, feijão-de-corda ou feijão-macassar [Vigna unguiculata (L.) Walp.] é uma das principais fontes de proteína para grande parte da população das regiões Norte e Nordeste do Brasil, e é cultivado, predominantemente, por agricultores familiares. A espécie é bastante versátil e pode ser comercializada na forma de grãos secos, grãos verdes, vagens verdes, farinha para acarajé e sementes (Rocha et al., 2007).

Atualmente, pesquisas realizadas por instituições públicas, como a Embrapa, têm permitido o lançamento de cultivares de feijão-caupi, as quais apresentam, além de resistência a diversas doenças, caracteres agronômicos altamente favoráveis à produção de grãos secos (Alcântara et al., 2002; Freire Filho et al., 2006). Essas cultivares têm, em geral, uma elevada resposta à irrigação e podem ser utilizadas tanto para a produção de grãos secos quanto de grãos verdes.

Blanco et al. (2011) avaliaram diferentes lâminas de irrigação para a produção de grãos verdes de feijão-caupi consorciado com o milho em Teresina, PI. Estes autores observaram que o feijão-caupi respondeu linearmente à irrigação e que a sua máxima produtividade foi obtida com lâmina de $640 \mathrm{~mm}$. Porém, são escassas as informações sobre o manejo

Pesq. agropec. bras., Brasília, v.47, n.4, p.576-583, abr. 2012 
ótimo da água de irrigação para a obtenção do máximo rendimento econômico da cultura.

A irrigação tem sido adotada em diversas culturas para suprir a demanda plena de água das plantas e maximizar a produtividade. Entretanto, segundo Frizzone (2004), uma mudança fundamental deverá ocorrer na prática da irrigação nos próximos anos, em decorrência das pressões econômicas sobre os agricultores, da crescente competição pelo uso da água e dos impactos ambientais causados pelo uso da irrigação. Esses fatores deverão motivar mudanças no paradigma da irrigação, com maior enfoque na eficiência econômica do que apenas no suprimento da demanda hídrica das plantas.

A eficiência econômica, com caráter maior de "otimização", compreende, explicitamente, aspectos econômicos, como custos e lucros, que não são normalmente considerados no manejo tradicional da irrigação, que tem sido praticado para maximizar a produtividade. No entanto, irrigar para maximizar o lucro é um problema substancialmente mais complexo e desafiador que irrigar somente para obter o máximo rendimento físico da cultura (Figueiredo et al., 2008). Para estes autores, uma irrigação ótima, sob o foco econômico, implica na aplicação de menores lâminas do que na irrigação plena, mesmo com a consequente redução de produtividade, mas com alguma vantagem econômica significativa. Esses benefícios potenciais advêm de três aspectos principais: aumento da eficiência da irrigação, redução dos custos e redução dos riscos associados aos impactos ambientais, em comparação à irrigação plena.

Um dos elementos básicos para estudos econômicos relativos ao planejamento de irrigação é a obtenção da função de resposta de produção da cultura à água (Andrade Júnior et al., 2001). A partir da função de resposta, é possível obter a solução ótima para uma determinada combinação insumo-produto, que possa maximizar a receita líquida do produtor.

Segundo Frizzone (1993), a definição de estratégias ótimas de irrigação, com base na análise econômica de funções de produção, pode considerar duas situações. Na primeira, a disponibilidade de terra é o único fator limitante da produção, e a água pode ser adquirida e aplicada a um custo unitário constante. A regra da otimização agroeconômica preconiza que a lâmina aplicada deva maximizar a receita liquida por unidade de área. Na segunda situação, a disponibilidade de água é o único fator que limita a produção. Nessa condição, a quantidade de terra é relativamente abundante e não limitante. A regra da otimização é atingir a máxima receita líquida por unidade de volume de água.

$\mathrm{Na}$ literatura, podem ser identificadas várias alternativas para definir o manejo ótimo da água de irrigação, que podem ser classificadas em dois grupos (Figueiredo et al., 2008). O primeiro diz respeito ao aumento da eficiência técnica, ou seja, maximizar a produtividade por unidade de volume de água aplicada. Nesse caso, o aumento da eficiência técnica pressupõe produzir o máximo com menor uso de água, o que é alcançado com a redução das perdas de água com a melhoria das estruturas de condução e distribuição de água e das técnicas de manejo da irrigação. $O$ segundo grupo está relacionado ao aumento da eficiência econômica, que significa obter o máximo retorno econômico por unidade de área cultivada ou por unidade de volume de água utilizada, dependendo da escassez relativa desses recursos. Enquanto a disponibilidade de terra for escassa em relação à água, o objetivo deverá ser selecionar a lâmina de irrigação que maximiza a receita líquida por unidade de área. No entanto, se a água for restrita em relação à terra, é preciso maximizar a receita líquida por unidade de volume de água.

Quando a água se constitui fator limitante à produção agrícola, a utilização de irrigação com a imposição de deficit hídrico controlado às plantas permite maior retorno econômico do que com a irrigação sem deficit hídrico (English, 1990). A definição de um intervalo de manejo da água de irrigação, a partir de uma função de produção conhecida, permite a utilização racional da irrigação com deficit hídrico controlado. A definição deste intervalo de manejo de irrigação, ao se considerar uma abordagem econômica, pode ser definida como uma estratégia ótima para o manejo da água.

O objetivo deste trabalho foi determinar estratégias ótimas de irrigação do feijão-caupi para a produção de grãos verdes, com a água como fator limitante da produção e diferentes valores de preço do produto.

\section{Material e Métodos}

O experimento foi conduzido na Embrapa Meio-Norte, em Teresina, PI $\left(5^{\circ} 05^{\prime} \mathrm{S}\right.$ e $42^{\circ} 29^{\prime} \mathrm{W}$, a $72 \mathrm{~m}$ de altitude), entre setembro e novembro de 
2009. O clima da região, de acordo com o balanço hídrico de Thornthwaite \& Mather (1955), é C1sA'a', caracterizado como subúmido seco, megatérmico, com excedente hídrico moderado no verão.

As características químicas e físico-hídricas do solo da área experimental estão descritas na Tabela 1.

Avaliaram-se as cultivares BRS Guariba e BRS Paraguaçu de feijão-caupi. O semeio das cultivares, realizado em 10/9/2009, foi feito com plantadeira manual, no espaçamento de $0,7 \times 0,2 \mathrm{~m}$. Quinze dias após a semeadura, foi realizado o desbaste, tendo-se deixado cinco plantas por metro linear.

A adubação de fundação foi realizada com base na análise de solo e consistiu na aplicação de $60 \mathrm{~kg} \mathrm{ha}^{-1} \mathrm{de}$ $\mathrm{P}_{2} \mathrm{O}_{5}$ e $40 \mathrm{~kg} \mathrm{ha}^{-1}$ de $\mathrm{K}_{2} \mathrm{O}$. Vinte dias após a semeadura, aplicaram-se $20 \mathrm{~kg} \mathrm{ha}^{-1}$ de $\mathrm{N}$ em cobertura. Os tratos culturais foram realizados para manter a cultura livre de plantas invasoras, doenças e pragas.

A irrigação foi efetuada por sistema de aspersão convencional fixo, com aspersores espaçados em $12 \times 12 \mathrm{~m}$.

Foram avaliadas cinco lâminas de irrigação, estabelecidas em função das seguintes frações da evapotranspiração de referência (ETo): 25, 50, 75, 100 e $125 \%$ da ETo. A ETo foi estimada pelo método de Penman-Monteith (Allen et al., 1998), e os dados climatológicos foram obtidos em estação

Tabela 1. Características químicas e físico-hídricas do solo da área experimental.

\begin{tabular}{|c|c|c|}
\hline \multirow[t]{2}{*}{ Característica } & \multicolumn{2}{|c|}{ Profundidade $(\mathrm{cm})$} \\
\hline & $0-20$ & $20-40$ \\
\hline $\mathrm{pH}$ em $\mathrm{H}_{2} \mathrm{O}$ & 5,78 & 5,37 \\
\hline Matéria orgânica $\left(\mathrm{g} \mathrm{kg}^{-1}\right)$ & 4,20 & 4,15 \\
\hline$P\left(\mathrm{mg} \mathrm{dm}^{-3}\right)$ & 33,80 & 14,10 \\
\hline $\mathrm{K}+\left(\mathrm{cmol}_{\mathrm{c}} \mathrm{dm}^{-3}\right)$ & 0,17 & 0,13 \\
\hline $\mathrm{Ca}^{2+}\left(\mathrm{cmol}_{\mathrm{c}} \mathrm{dm}^{-3}\right)$ & 1,47 & 1,79 \\
\hline $\mathrm{Mg}^{2+}\left(\mathrm{cmol}_{\mathrm{c}} \mathrm{dm}^{-3}\right)$ & 0,76 & 0,58 \\
\hline $\mathrm{Na}^{+}\left(\mathrm{cmol}_{\mathrm{c}} \mathrm{dm}^{-3}\right)$ & 0,01 & 0,01 \\
\hline $\mathrm{H}^{+}+\mathrm{Al}^{3+}\left(\mathrm{cmol}_{\mathrm{c}} \mathrm{dm}^{-3}\right)$ & 2,15 & 3,38 \\
\hline Capacidade de troca catiônica $\left(\mathrm{cmol}_{\mathrm{c}} \mathrm{dm}^{-3}\right)$ & 4,56 & 5,89 \\
\hline Saturação por bases (\%) & 52,91 & 42,60 \\
\hline Densidade $\left(\mathrm{kg} \mathrm{dm}^{-3}\right)$ & 1,23 & 1,4 \\
\hline Areia grossa $\left(\mathrm{g} \mathrm{kg}^{-1}\right)$ & 785 & 434 \\
\hline Areia fina $\left(\mathrm{g} \mathrm{kg}^{-1}\right)$ & 95 & 191 \\
\hline Silte $\left(\mathrm{g} \mathrm{kg}^{-1}\right)$ & 35 & 170 \\
\hline Argila $\left(\mathrm{g} \mathrm{kg}^{-1}\right)$ & 86 & 206 \\
\hline Capacidade de campo $\left(\mathrm{cm}^{3} \mathrm{~cm}^{-3}\right)$ & 0,22 & 0,22 \\
\hline Ponto de murcha permanente $\left(\mathrm{cm}^{3} \mathrm{~cm}^{-3}\right)$ & 0,09 & 0,11 \\
\hline
\end{tabular}

agrometeorológica automática a cerca de $500 \mathrm{~m}$ da área experimental.

Utilizou-se o delineamento experimental de blocos ao acaso, com quatro repetições e tratamentos dispostos em parcelas subdivididas, em que as lâminas de irrigação foram distribuídas nas parcelas experimentais e as cultivares nas subparcelas.

A irrigação foi uniforme para permitir o estabelecimento das plantas em todas as parcelas experimentais, durante os primeiros 30 dias após a semeadura, tendo sido realizada diariamente, com lâmina de água aplicada igual à ETo. Os tratamentos de irrigação foram iniciados a partir do trigésimo primeiro dia após a semeadura e se estenderam até a colheita.

Cada tratamento foi constituído por quatro blocos, formados por sete fileiras de plantas de $7,0 \mathrm{~m}$ de comprimento. A área útil avaliada em cada subparcela experimental foi formada pelas três fileiras centrais, tendo-se eliminado $1,0 \mathrm{~m}$ em cada extremidade $\left(3,5 \mathrm{~m}^{2}\right)$.

O teor de água no solo foi monitorado diariamente, em camadas de 0,10 a $0,70 \mathrm{~m}$ de profundidade, por meio da sonda de capacitância elétrica, Diviner 2000 (Senteck, Adelaide, Austrália). Instalaram-se três tubos de acesso para medição do teor de água no solo, para cada tratamento.

A lâmina média de irrigação efetivamente aplicada em cada tratamento foi determinada imediatamente após cada irrigação, com base nas medições realizadas em 16 coletores espaçados em 3,0x3,0 m.

A colheita foi realizada 56 e 60 dias após a semeadura, quando as vagens estavam bem intumescidas e começavam a sofrer leve mudança de tonalidade. Ao final da colheita, as vagens foram debulhadas, e foi avaliada a produtividade de grãos verdes.

As funções de produção água-cultura para o feijão-caupi foram determinadas ao se relacionar as lâminas de irrigação aplicadas com as produtividades de grãos verdes obtidas, conforme Bernardo (1998). Para tal, utilizou-se a seguinte função de produção água-cultura do tipo polinomial de segundo grau: $\mathrm{Y}(\mathrm{w})=\mathrm{a}_{1}+\mathrm{b}_{1}+\mathrm{c}_{1} \mathrm{w}^{2}$, em que: $\mathrm{Y}(\mathrm{w})$ é a produtividade de grãos verdes; w é a lâmina de água; e $a_{1}, b_{1}$ e c $c_{1}$ são os coeficientes da equação de regressão.

Para a função de custo de produção linear, assumiuse, como condição simplificadora, que a soma dos 
custos fixos com os custos indiretamente dependentes da quantidade de água aplicada é constante, conforme English (1990): C(w) $=\mathrm{Co}+\mathrm{Cw} \times \mathrm{W}$, em que: $\mathrm{C}(\mathrm{w})$ é o custo total de produção por unidade de área irrigada (US\$ ha ${ }^{-1}$ ); Co é a soma dos custos fixos com os custos indiretamente dependentes da irrigação (US\$ ha-1); $\mathrm{CW}$ é o custo da água de irrigação (US $\$ \mathrm{~mm}^{-1} \mathrm{ha}^{-1}$ ); e W é a lâmina de irrigação (mm).

Para a determinação das estratégias ótimas de irrigação, utilizou-se a metodologia proposta por English (1990), que consiste na definição das lâminas máxima, ótima e equivalente para cada combinação de preço do produto e custo da água. A lâmina máxima $\left(\mathrm{W}_{\mathrm{m}}\right)$ proporciona a máxima produtividade fisiológica; a lâmina ótima $\left(\mathrm{W}_{\mathrm{o}}\right)$, a máxima receita líquida por volume de água aplicado, para um dado preço do produto $(\mathrm{Pc})$ e preço da água $(\mathrm{Cw})$; e a lâmina equivalente (We) proporciona uma receita líquida igual à lâmina máxima, conforme descrito pelas equações a seguir: $\mathrm{W}_{\mathrm{m}}=-\mathrm{b}_{1} / 2 \mathrm{a}_{1} ; \mathrm{W}_{\mathrm{o}}=\left(\mathrm{P}_{\mathrm{c}} \mathrm{a}_{1}-\mathrm{a}_{2}\right)^{1 / 2} / \mathrm{P}_{\mathrm{c}} \times \mathrm{c}_{1} \mathrm{e}$ $\mathrm{We}=-\mathrm{Z}+\left[\mathrm{Z}^{2}-4 \mathrm{P}_{\mathrm{c}} \mathrm{c}_{1}\left(\mathrm{P}_{\mathrm{c}} \mathrm{a}_{1}-\mathrm{a}_{2}\right)^{1 / 2}\right] / \mathrm{P}_{\mathrm{c}} \times \mathrm{c}_{1}$, sendo: $\mathrm{Z}=\mathrm{P}_{\mathrm{c}} \mathrm{b}_{1}{ }^{2}-4 \mathrm{a}_{2} \mathrm{c}_{1}+4 \mathrm{P}_{\mathrm{c}} \mathrm{a}_{1} \mathrm{c}_{1} / 2 \mathrm{~b}^{1}$, em que: $\mathrm{a}_{1}, \mathrm{~b}_{1}$ e $\mathrm{c}_{1}$ são os coeficientes da função de produção; $\mathrm{a}_{2}$ e $\mathrm{b}_{2}$ são os coeficientes da função de custo; e $\mathrm{P}_{\mathrm{c}}$ é o preço do produto.

A receita líquida, para cada combinação de preço do produto $(\mathrm{Pc})$ e preço da água $(\mathrm{Cw})$, foi determinada com uso da equação (Andrade Júnior et al., 2001): $\mathrm{RL}=\left[\mathrm{P}_{\mathrm{c}} \mathrm{Yw}_{\mathrm{i}}-\left(\mathrm{Co}+\mathrm{CwW}_{\mathrm{i}}\right)\right] / 10 \mathrm{~W}_{\mathrm{i}}$, em que: RL é a receita líquida obtida com a aplicação da lâmina $\mathrm{W}_{\mathrm{i}}\left(\mathrm{US} \$ \mathrm{~m}^{-3}\right) ; \mathrm{P}_{\mathrm{c}}$ é o preço do produto (US\$ $\mathrm{kg}^{-1}$ ); $\mathrm{Yw}_{\mathrm{i}}$ é a produção obtida com a aplicação da lâmina $\mathrm{W}_{\mathrm{i}}\left(\mathrm{kg} \mathrm{ha}^{-1}\right)$; Co é a soma dos custos fixos com os custos indiretamente dependentes da irrigação (US\$ ha-1); $\mathrm{Cw}$ é o custo da água de irrigação (US\$ $\mathrm{mm}^{-1} \mathrm{ha}^{-1}$ ); e $W_{i}$ é a lâmina máxima, ótima ou equivalente de irrigação (mm).

Para o cálculo da água economizada pela irrigação $\Delta\left(\mathrm{W}_{\mathrm{i}}\right)$, da área adicional $\Delta(\mathrm{A})$ e da produção adicional $\Delta \mathrm{Y}(\mathrm{w})$, utilizaram-se as equações: $\Delta\left(\mathrm{W}_{\mathrm{i}}\right)=\mathrm{W}_{\mathrm{m}}-\mathrm{W}_{\mathrm{i} .}$; $\Delta\left(\mathrm{A}_{\mathrm{i}}\right)=\left(\Delta\left(\mathrm{W}_{\mathrm{i}}\right) / \mathrm{W}_{\mathrm{i}}\right)$ e $\Delta \mathrm{Y}(\mathrm{w})=\Delta\left(\mathrm{A}_{\mathrm{i}}\right) \times \mathrm{Yw}_{\mathrm{i}}$, em que: $\Delta \mathrm{W}_{\mathrm{i}}$ é a água economizada com a aplicação da lâmina $\mathrm{W}_{\mathrm{i}}(\mathrm{mm})$, em comparação à aplicação da lâmina máxima; $\mathrm{W}_{\mathrm{m}}$ é a lâmina máxima $(\mathrm{mm}) ; \mathrm{W}_{\mathrm{i}}$ é a lâmina ótima ou equivalente de irrigação $(\mathrm{mm}) ; \Delta\left(\mathrm{A}_{\mathrm{i}}\right)$ é a área adicional para irrigação com a água economizada (ha); $\Delta \mathrm{Y}(\mathrm{w})$ é a produção adicional obtida com a aplicação da lâmina economizada $\left(\mathrm{kg} \mathrm{ha}^{-1}\right)$; e $\mathrm{Yw}_{\mathrm{i}}$ é a produção obtida com a aplicação da lâmina ótima ou equivalente $\left(\mathrm{kg} \mathrm{ha}^{-1}\right)$.

O preço da água estimado em função do preço do quilowatt-hora $(\mathrm{kWh})$ de energia elétrica, em outubro de 2010, foi de R\$ $0,320 \mathrm{kWh}^{-1}$ ou US\$ $0,188 \mathrm{kWh}^{-1}$ (Eletrobrás Distribuição Piauí, 2009), convertido em dólar à taxa de câmbio $\mathrm{R} \$ 1,70$ por US\$ 1,0 , que representa o valor cobrado para a tarifa rural irrigante sem os subsídios da Lei Estadual de incentivo à irrigação. $\mathrm{O}$ consumo médio de energia elétrica, para cada lâmina de irrigação, foi obtido em função do tempo de irrigação durante o experimento de campo, com uso de motobomba elétrica trifásica, modelo 9-DC (Inapi, Fortaleza, CE), de 5 CV/3500 RPM em kWh ha' ${ }^{-1}$, ajustada por meio de equação de regressão (Figura 1).

Assim, os custos da água para cada lâmina de irrigação avaliada, que expressou apenas o custo de energia para bombeamento, foram obtidos pela seguinte equação: $\mathrm{Cw}=(\mathrm{CEE} / \mathrm{LL}) \times \mathrm{Pe}$, em que: $\mathrm{Cw}$ é o custo da água de irrigação (US\$ $\mathrm{mm}^{-1} \mathrm{ha}^{-1}$ ); CEE é o consumo de energia elétrica durante o ciclo da cultura $\left(\mathrm{kWh} \mathrm{ha}^{-1}\right)$; LL é a lâmina de irrigação total aplicada (mm); e Pe é o preço do quilowatt-hora de energia elétrica $\left(\mathrm{US} \$ \mathrm{kWh}^{-1}\right)$.

$\mathrm{O}$ custo médio de produção do feijão-caupi $(\mathrm{Co})$, tendo-se excetuado o custo da água de irrigação, considerado na análise, foi de US\$ $882,35 \mathrm{ha}^{-1}$, para condições de solo arenoso e de baixa fertilidade natural do Estado do Piauí (Andrade Júnior et al., 2003).

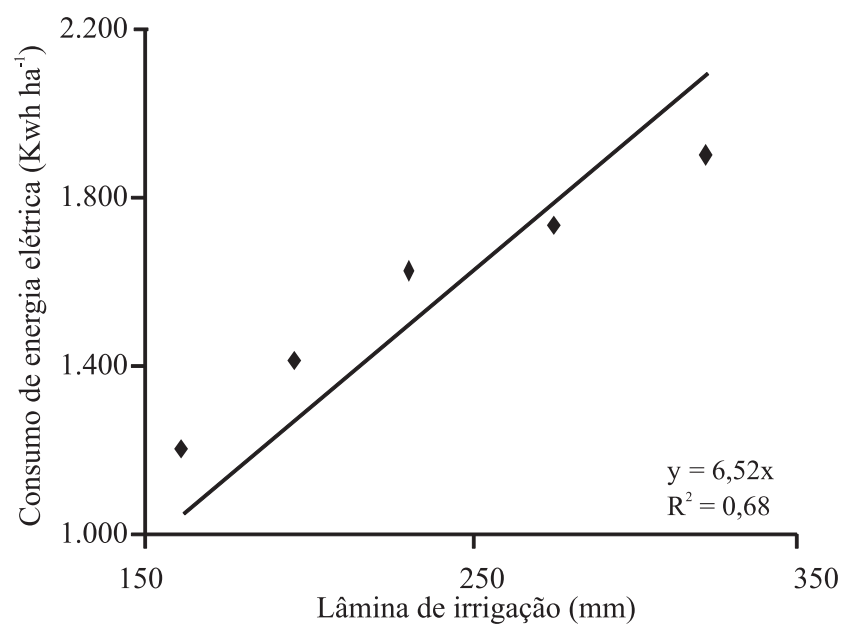

Figura 1. Consumo médio de energia elétrica (CEE) em função das lâminas de irrigação. 
O preço médio mensal dos grãos verdes do feijão-caupi, no período de janeiro de 2008 a julho de 2010, no mercado atacadista de Teresina, fornecido pela Central de Abastecimento do Piauí S/A, variou de US\$ 0,70 a US\$ $1,50 \mathrm{~kg}^{-1}$.

Por se tratarem de fatores quantitativos, procedeuse à análise de regressão, tendo-se relacionado as lâminas de irrigação com a produtividade de grãos verdes. Aplicou-se o teste t para avaliar a significância dos coeficientes da regressão, com uso do programa SAS (SAS Institute, 2002).

\section{Resultados e Discussão}

A aplicação das frações de 25, 50, 75, 100 e 125\% da ETo resultou nas seguintes lâminas totais de irrigação: $161 \mathrm{~mm}$ (L1), $196 \mathrm{~mm}$ (L2), $231 \mathrm{~mm}$ (L3), $275 \mathrm{~mm}$ (L4) e $322 \mathrm{~mm}$ (L5), para as duas cultivares avaliadas. Ressalta-se que durante o período experimental não houve precipitação pluvial, de modo que a resposta produtiva ocorreu apenas em função das lâminas de irrigação.

Os coeficientes da análise de regressão (Tabela 2) foram significativos para a produtividade de grãos em relação às lâminas de irrigação, tanto para a cultivar BRS Guariba como para a BRS Paraguaçu.

Esses resultados são semelhantes aos obtidos por Nascimento et al. (2004), ao avaliar o efeito da variação de níveis de água disponível no solo (40, 60, 80 e $100 \%$ ), sobre o crescimento e a produtividade de vagens e grãos verdes do feijão-caupi, cultivar IPA 206, em Areia, PB. De acordo com estes autores, os diferentes níveis de água disponível no solo influenciaram significativamente $\mathrm{o}$ crescimento das plantas e a produtividade de grãos verdes do feijão-caupi.

As funções de produção água-cultura para o feijão-caupi, cultivares BRS Guariba e BRS Paraguaçu, ajustaram-se a equações polinomiais quadráticas
(Figura 2), e as lâminas que proporcionaram a máxima produtividade física de grãos verdes foram as de 423 e $354 \mathrm{~mm}$, respectivamente, para as cultivares BRS Paraguaçu $\left(2.492,86 \mathrm{~kg} \mathrm{ha}^{-1}\right)$ e BRS Guariba $\left(2.937,36 \mathrm{~kg} \mathrm{ha}^{-1}\right)$. Essas lâminas de irrigação estão abaixo das obtidas por Blanco et al. (2011), que avaliaram diferentes lâminas de irrigação para a produção de grão verde do feijão-caupi consorciado com o milho.

Os valores das lâminas ótimas (Wo) e equivalentes (We) foram obtidos em função da variação do preço do feijão-caupi (Figura 3). Verificou-se que à medida que o preço do produto aumenta, as lâminas Wo e We diminuem, o que aumenta o intervalo de manejo econômico da água. Dessa forma, a economia de água com a aplicação de Wo ou We varia de acordo com o preço do produto. Comportamento semelhante foi verificado por Andrade Júnior et al. (2001).

As estratégias ótimas de irrigação e os valores das lâminas máxima, ótima e equivalente, bem como as respectivas receitas líquidas, foram obtidas em razão das diferentes combinações de preço do feijão-caupi e custo fixo de água, para as duas cultivares avaliadas (Tabela 3).

Os intervalos de lâmina de irrigação que maximizaram a receita líquida para a produção de grãos verdes foram de 290 a $325 \mathrm{~mm}$, para a cultivar BRS Guariba, e de 325 a $363 \mathrm{~mm}$, para a cultivar BRS Paraguaçu, ao se considerar a faixa de preços de US\$ 0,50 a US\$ 2,00.

Os valores inferiores para cada preço do produto representam as We, enquanto os valores superiores correspondem às lâminas que maximizam a produção (Wm) e os centrais representam as lâminas que otimizam a receita liquida do produtor (Wo).

Dependendo do custo do feijão-caupi, os intervalos de lâmina de irrigação que viabilizam economicamente a produção de grãos verdes foram de 250 a $423 \mathrm{~mm}$,

Tabela 2. Análises de regressão da produtividade de grãos verdes das cultivares de feijão-caupi BRS Paraguaçu e BRS Guariba, em função das lâminas de irrigação aplicadas.

\begin{tabular}{|c|c|c|c|c|c|c|}
\hline Cultivar & Variação & GL & Parâmetros estimados & Erro & Valor $(\mathrm{t})$ & $\operatorname{Pr}>t$ \\
\hline \multirow{3}{*}{ BRS Guariba } & Intercepto & 1 & $-4.695,07$ & $1.580,16$ & $-2,97$ & 0,0086 \\
\hline & Coeficiente a & 1 & $-0,061$ & 0,028 & $-2,18$ & 0,0438 \\
\hline & Coeficiente b & 1 & 43,14 & 13,607 & 3,17 & 0,0056 \\
\hline \multirow{3}{*}{ BRS Paraguaçu } & Intercepto & 1 & -2.518 & $1.447,21$ & $-2,70$ & 0,0153 \\
\hline & Coeficiente a & 1 & $-0,028$ & 0,0256 & $-2,17$ & 0,0095 \\
\hline & Coeficiente $\mathrm{b}$ & 1 & 23,695 & 12,46277 & 2,92 & 0,0441 \\
\hline
\end{tabular}

Pesq. agropec. bras., Brasília, v.47, n.4, p.576-583, abr. 2012 
para a cultivar BRS Paraguaçu, e de 238 a $354 \mathrm{~mm}$, para a cultivar BRS Guariba.

Entretanto, para o preço na faixa de US\$ $0,50 \mathrm{~kg}^{-1}$ a US\$ 2,00 $\mathrm{kg}^{-1}$, para a cultivar BRS Guariba, e de US\$ $0,75 \mathrm{~kg}^{-1}$ a US\$ $2,00 \mathrm{~kg}^{-1}$, para a cultivar BRS Paraguaçu, a adoção de estratégia para o manejo econômico de irrigação mostrou-se viável. Por exemplo, com o preço do produto a US $\$ 1,00$ o quilo, as receitas líquidas de 0,29 US\$ $\mathrm{m}^{-3}$ (BRS Paraguaçu) e 0,50 US\$ $\mathrm{m}^{-3}$ (BRS Guariba), obtidas com as

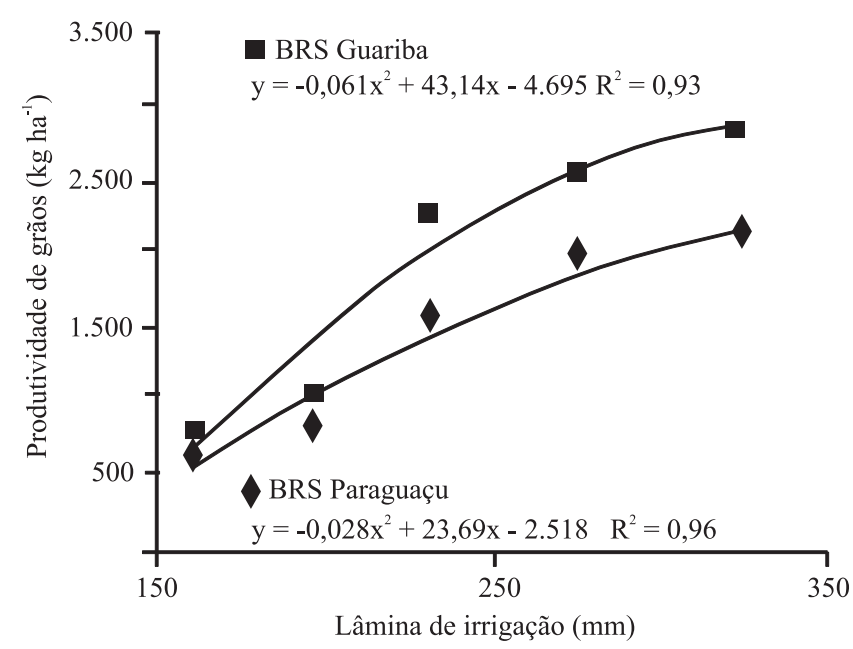

Figura 2. Produtividade de grãos verdes das cultivares de feijão caupi BRS Paraguaçu e BRS Guariba, em função das lâminas de irrigação aplicadas.

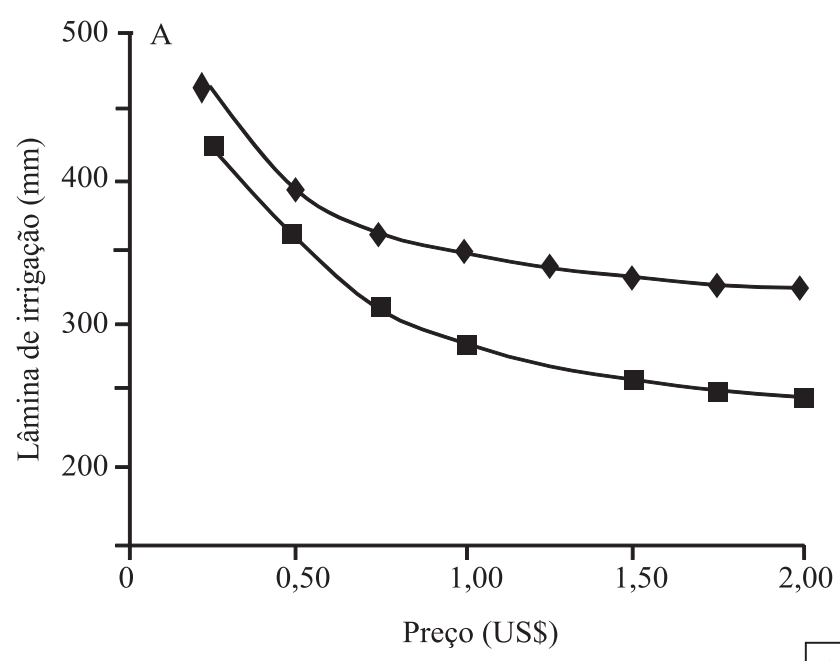

$\diamond$ Wo $\square$ We lâminas ótimas, superaram em 8 e $8,7 \%$ as receitas liquidas de 0,26 US\$ $\mathrm{m}^{-3}$ (BRS Paraguaçu) e

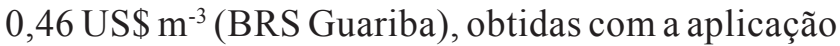
das lâminas que proporcionaram as máximas produções.

Para o preço do produto a US\$ $1,00 \mathrm{~kg}^{-1}$, as lâminas ótimas são as de $348,5 \mathrm{~mm}$, para a cultivar BRS Paraguaçu, e de $302,4 \mathrm{~mm}$, para a cultivar BRS Guariba (Tabela 3). Esses valores correspondem a uma economia de água, em relação às lâminas que proporcionaram máxima produção, de 74,55 e $51,34 \mathrm{~mm}$, respectivamente, para as cultivares BRS Paraguaçu (423,0 mm) e BRS Guariba (353,8 mm). Com essa economia de água, é possível aumentar em 0,21 e 0,17 ha a área a ser irrigada, o que gera uma produtividade adicional de 490,82 e 471,40 $\mathrm{kg} \mathrm{ha}^{-1}$, para as cultivares BRS Paraguaçu e BRS Guariba, respectivamente. Ressalta-se que a qualidade dos grãos verdes não foi afetada pela adoção da estratégia para o manejo econômico da irrigação.

Para uma mesma combinação de preço do produto e custo da água, a cultivar BRS Guariba proporcionou maior receita liquida e maior produtividade de grãos verdes, quando comparada à cultivar BRS Paraguaçu, que é indicada para ser usada, preferencialmente, na produção de grãos verdes.

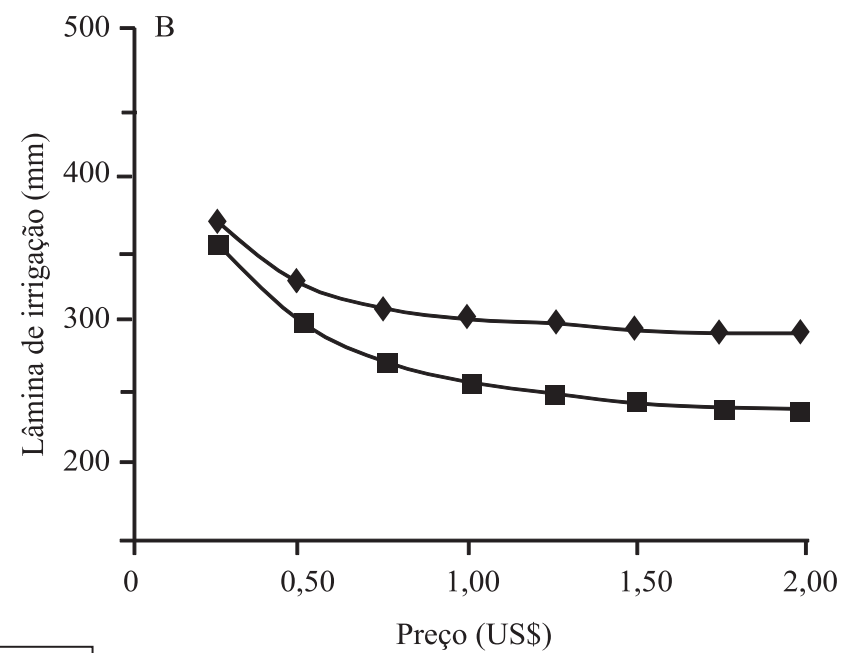

Figura 3. Lâminas ótimas (Wo) e equivalentes (We) em função do preço do produto das cultivares de feijão-caupi A, BRS Paraguaçu e B, BRS Guariba. 
Tabela 3. Estratégias de irrigação, lâminas máxima, ótima e equivalente e respectivas receitas líquidas (RL), com as diferentes combinações de preço do produto, ao se considerar o custo da água (Cw) de US\$1,25 ( $\left.\mathrm{mm} \mathrm{ha}^{-1}\right)$, das cultivares de feijão-caupi BRS Paraguaçu e BRS Guariba.

\begin{tabular}{|c|c|c|c|c|c|c|}
\hline $\begin{array}{l}\text { Preço do produto } \\
\left(\mathrm{US} \$ \mathrm{~kg}^{-1}\right)\end{array}$ & $\begin{array}{c}\mathrm{W}_{\mathrm{i}} \\
(\mathrm{mm})\end{array}$ & $\begin{array}{c}\mathrm{Y}(\mathrm{w}) \\
\left(\mathrm{kg} \mathrm{ha}^{-1}\right)\end{array}$ & $\begin{array}{c}\mathrm{RL} \\
\left(\mathrm{US} \$ \mathrm{~m}^{-3}\right)\end{array}$ & $\begin{array}{l}\Delta\left(\mathrm{W}_{\mathrm{i}}\right) \\
(\mathrm{mm})\end{array}$ & $\begin{array}{l}\Delta(\mathrm{A}) \\
\text { (ha) }\end{array}$ & $\begin{array}{c}\Delta \mathrm{Y}(\mathrm{w}) \\
\left(\mathrm{kg} \mathrm{h}^{-1}\right)\end{array}$ \\
\hline \multicolumn{7}{|c|}{ BRS Paraguaçu } \\
\hline \multirow{3}{*}{0,75} & 423,0 & $2.492,86$ & 0,11 & 0,00 & 1,00 & 0,00 \\
\hline & 363,2 & $2.392,75$ & 0,13 & 59,79 & 1,16 & 382,84 \\
\hline & 311,9 & $2.147,03$ & 0,11 & 111,13 & 1,36 & 772,93 \\
\hline \multirow{3}{*}{1,00} & 423,0 & $2.492,86$ & 0,26 & 0,00 & 1,00 & 0,00 \\
\hline & 348,5 & $2.337,24$ & 0,29 & 74,55 & 1,21 & 490,82 \\
\hline & 287,1 & $1.975,23$ & 0,26 & 135,97 & 1,55 & $1.086,3$ \\
\hline \multirow{3}{*}{1,25} & 423,0 & $2.492,86$ & 0,40 & 0,00 & 1,00 & 0,00 \\
\hline & 339,3 & $2.296,63$ & 0,46 & 83,71 & 1,27 & 620,09 \\
\hline & 272,2 & $1.855,58$ & 0,40 & 150,86 & 1,55 & $1.020,5$ \\
\hline \multirow{3}{*}{1,50} & 423,0 & $2.492,86$ & 0,55 & 0,00 & 1,00 & 0,00 \\
\hline & 333,1 & $2.266,24$ & 0,63 & 89,96 & 1,27 & 611,88 \\
\hline & 262,2 & $1.768,91$ & 0,55 & 160,80 & 1,61 & $1.079,0$ \\
\hline \multirow{3}{*}{1,75} & 423,0 & $2.492,86$ & 0,70 & 0,00 & 1,00 & 0,00 \\
\hline & 328,5 & $2.242,81$ & 0,80 & 94,50 & 1,29 & 650,41 \\
\hline & 255,1 & $1.703,62$ & 0,70 & 167,89 & 1,66 & $1.124,3$ \\
\hline \multirow{3}{*}{2,00} & 423,0 & $2.492,86$ & 0,84 & 0,00 & 1,00 & 0,00 \\
\hline & 325,1 & $2.224,25$ & 0,97 & 97,94 & 1,30 & 667,28 \\
\hline & 249,8 & $1.652,80$ & 0,84 & 173,21 & 1,69 & $1.140,43$ \\
\hline \multirow{4}{*}{0,50} & \multicolumn{6}{|c|}{ BRS Guariba } \\
\hline & 353,8 & $2.937,37$ & 0,04 & 0,00 & 1,00 & 0,00 \\
\hline & 325,5 & $2.888,50$ & 0,05 & 28,30 & 1,09 & 259,97 \\
\hline & 299,4 & $2.757,24$ & 0,04 & 54,34 & 1,18 & 500,43 \\
\hline \multirow{3}{*}{0,75} & 353,8 & $2.937,37$ & 0,25 & 0,00 & 1,00 & 0,00 \\
\hline & 310,3 & $2.822,10$ & 0,27 & 43,47 & 1,14 & 395,35 \\
\hline & 272,2 & $2.531,21$ & 0,25 & 81,60 & 1,30 & 758,81 \\
\hline \multirow{3}{*}{1,00} & 353,8 & $2.937,37$ & 0,46 & 0,00 & 1,00 & 0,00 \\
\hline & 302,4 & $2.776,59$ & 0,50 & 51,34 & 1,17 & 471,40 \\
\hline & 258,5 & $2.384,20$ & 0,46 & 95,23 & 1,37 & 878,33 \\
\hline \multirow{3}{*}{1,25} & 353,8 & $2.937,37$ & 0,66 & 0,00 & 1,00 & 0,00 \\
\hline & 297,6 & $2.744,97$ & 0,73 & 56,16 & 1,19 & 521,54 \\
\hline & 250,4 & $2.285,11$ & 0,66 & 103,41 & 1,41 & 936,90 \\
\hline \multirow{3}{*}{1,50} & 353,8 & $2.937,37$ & 0,87 & 0,00 & 1,00 & 0,00 \\
\hline & 294,4 & $2.722,00$ & 0,96 & 59,42 & 1,20 & 544,40 \\
\hline & 244,9 & $2.214,53$ & 0,87 & 108,86 & 1,44 & 974,39 \\
\hline \multirow{3}{*}{1,75} & 353,8 & $2.937,37$ & 1,08 & 0,00 & 1,00 & 0,00 \\
\hline & 292,0 & $2.704,64$ & 1,19 & 61,77 & 1,21 & 567,97 \\
\hline & 241,0 & $2.161,89$ & 1,08 & 112,75 & 1,47 & $1.016,09$ \\
\hline \multirow{3}{*}{2,00} & 353,8 & $2.937,37$ & 1,29 & 0,00 & 1,00 & 0,00 \\
\hline & 290,2 & $2.691,07$ & 1,43 & 63,54 & 1,22 & 592,04 \\
\hline & 238,1 & $2.121,19$ & 1,29 & 115,67 & 1,49 & $1.039,38$ \\
\hline
\end{tabular}

${ }^{(1)} \mathrm{W}_{\mathrm{i}}$, lâmina máxima, ótima ou equivalente de irrigação; $\mathrm{Y}(\mathrm{w})$, produtividade de grãos verdes; $\Delta\left(\mathrm{W}_{\mathrm{i}}\right)$, água economizada pela irrigação; $\Delta(\mathrm{A})$, área adicional para irrigação com a água economizada; e $\Delta \mathrm{Y}(\mathrm{w})$, produção adicional obtida com a aplicação da lâmina economizada.

\section{Conclusões}

1. A adoção de estratégia para o manejo econômico da irrigação do feijão-caupi, para produtividade de grãos verdes, mostra-se plenamente viável na faixa de variação de preço de produto de US\$ $0,75 \mathrm{~kg}^{-1}$ a US\$ $2,00 \mathrm{~kg}^{-1}$ e US\$ $0,50 \mathrm{~kg}^{-1}$ a US\$ $2,00 \mathrm{~kg}^{-1}$, para as cultivares BRS Paraguaçu e BRS Guariba, respectivamente.

2. Os intervalos de lâmina de irrigação que maximizam a receita líquida para a produção de grãos verdes são de 290 a $325 \mathrm{~mm}$, para a cultivar BRS Guariba, e de 325 a $363 \mathrm{~mm}$, para a cultivar BRS Paraguaçu. 
3. A cultivar BRS Guariba mostra melhor desempenho econômico e produtivo, no que concerne às receitas líquidas e às produtividades de grãos verdes, quando comparada à cultivar BRS Paraguaçu.

\section{Referências}

ALCÂNTARA, J. dos P.; MONTEIRO, I.D.; VASCONCELOS, O.L.; FREIRE FILHO, F.R.; RIBEIRO, V.Q. BRS Paraguaçu, novo cultivar de caupi de porte "enramador" e tegumento branco para o Estado da Bahia. Revista Ceres, v.49, p.695-703, 2002.

ALlEN, R.G.; PEREIRA, L.S.; RAES, D.; SMITH, M. Crop evapotranspiration: guidelines for computing crop water requirements. Rome: FAO, 1998. 300p. (FAO. Irrigation and drainage paper, 56).

ANDRADE JÚNIOR, A.S. de; FRIZZONE, J.A.; BASTOS, E.A.; CARDOSO, M.J.; RODRIGUES, B.H.N. Estratégias ótimas de irrigação para a cultura da melancia. Pesquisa Agropecuária Brasileira, v.36, p.301-305, 2001.

ANDRADE JÚNIOR, A.S. de; SANTOS, A.A. dos; SOBRINHOS, C.A.; BASTOS, E.A.; MELO, F. de B.; PINTO VIANA, F.M.; FREIRE FILHO, F.R.; CARNEIRO, J. da S.; ROCHA, M. de M.; CARDOSO, M.J.; SILVA, P.H.S. da.; RIBEIRO, V.Q. Cultivo de feijão-caupi. Teresina: Embrapa Meio-Norte, 2003. (Embrapa Meio-Norte. Sistemas de produção, 2). Disponível em: <http:// sistemasdeproducao.cnptia.embrapa.br/FontesHTML/Feijao/ FeijaoCaupi/coeficientestecnicos.htm>. Acesso em: 18 nov. 2009.

BERNARDO, S. Irrigação e produtividade. In: FARIA, M.A. de (Coord.). Manejo de irrigação. Poços de Caldas: SBEA: UFLA, 1998. p.117-132.

BLANCO, F.F.; CARDOSO, M.J.; FREIRE FILHO, F.R.; VELOSO, M.E. da C.; NOGUEIRA, C.C.P.; DIAS, N. da DIAS, N. da S. Milho verde e feijão-caupi cultivados em consórcio sob diferentes lâminas de irrigação e doses de fósforo. Pesquisa Agropecuária Brasileira, v.46, p.524-530, 2011.

ELETROBRÁS DISTRIBUIÇÃO PIAUÍ. Tarifas - set/2009. Teresina: Cepisa, 2009. Disponível em: < http://www.cepisa.com. br/cepisa/sv_tarifas.php>. Acesso em: $20 \mathrm{dez} .2009$.

ENGLISH, M.J. Deficit irrigation. I. Analytical framework. Journal of Irrigation and Drainage Engineering, v.116, p.339-412, 1990.

FIGUEIREDO, M.G. de; FRIZZONE, J.A.; PITELlI, M.M.; REZENDE, R. Lâmina ótima de irrigação do feijoeiro, com restrição de água, em função do nível de aversão ao risco do produtor. Acta Scientiarum. Agronomy, v.30, p.81-87, 2008.

FREIRE FILHO, F.R.; ROCHA, M. de M.; BRIOSO, P.S.T.; RIBEIRO, V.Q. 'BRS Guariba': white-grain cowpea cultivar for the mid-north region of Brazil. Crop Breeding and Applied Biotechnology, v.6, p.175-178, 2006.

FRIZZONE, J.A. Funções de resposta das culturas à irrigação. Piracicaba: ESALQ, 1993. 42p.

FRIZZONE, J.A. Otimização do uso da água na agricultura irrigada: perspectivas e desafios. Engenharia Rural, v.15, p.37-56, 2004.

NASCIMENTO, J.T.; PEDROSA, M.B.; TAVARES SOBRINHO, J. Efeito da variação de níveis de água disponível no solo sobre o crescimento e produção de feijão-caupi, vagens e grãos verdes. Horticultura Brasileira, v.22, p.174-177, 2004.

ROCHA, M. de M.; SOARES, M. da C.; FREIRE FILHO, F.R.; RAMOS, S.R.R.; RIBEIRO, V.Q. Avaliação preliminar de genótipos de feijão-caupi para feijão-verde. Revista Científica Rural, v.12, p.153-156, 2007.

SAS INSTITUTE. SAS/STAT: user's guide. Version 8.1. Cary: SAS Institute, 2002. v.1, 890p.

THORNTHWAITE, C.W.; MATHER, J.R. The water balance. Centerton: Drexel Institute of Technology, 1955. 104p. (Publications in climatology).

Recebido em 16 de dezembro de 2011 e aprovado em 22 de março de 2012 